\title{
Total saponins of Bolbostemma paniculatum (maxim.) Franquet exert antitumor activity against MDA-MB-231 human breast cancer cells via inhibiting PI3K/Akt/mTOR pathway
}

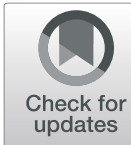

Jian-Wei Dou ${ }^{1,2}$, Rong-Guo Shang ${ }^{1,2}$, Xiao-Qin Lei ${ }^{3,4}$, Kang-Le Li ${ }^{1,2}$, Zhan-Zi Guo ${ }^{5}, K_{a i}$ Ye $^{5}$, Xiao-Juan Yang ${ }^{5}$, Yu-Wei Li, ${ }^{3,4}$, Yun-Yun Zhou ${ }^{3,4}$, Jia Yao ${ }^{6}$ and Qian Huang ${ }^{6 *}$

\begin{abstract}
Background: The aim of the present study was to examine the effects of the Bolbostemma paniculatum (Maxim.) Franquet (BP) active compound, BP total saponins (BPTS), on MDA-MB-231 cells, and investigate the underlying mechanism regarding BPTS-mediated attenuation of the PI3K/Akt/mTOR pathway.

Methods: The effect of BPTS on cytotoxicity, induction of apoptosis and migration on MDA-MB-231 cells at three different concentrations was investigated. A CCK-8 assay, wound-healing assay and flow cytometry were used to demonstrate the effects of BPTS. Additionally, expression of the primary members of the PI3K/Akt/mTOR signaling pathway was assessed using western blotting. To verify the underlying mechanisms, a PI3K inhibitor and an mTOR inhibitor were used.

Results: BPTS inhibited proliferation of MDA-MB-231 cells with an $I C_{50}$ value of $10 \mu \mathrm{g} / \mathrm{mL}$ at $48 \mathrm{~h}$. BPTS inhibited migration of MDA-MB-231 cells, and the western blot results demonstrated that BPTS reduced p-PI3K, p-Akt and p-mTOR protein expression levels in MDA-MB-231 cells. Additionally, the results were confirmed using a PI3K inhibitor and an mTOR inhibitor. BPTS decreased proliferation and migration of MDA-MB-231 cells possibly through inhibiting the PI3K/Akt/mTOR signaling pathway.
\end{abstract}

Conclusions: The results highlight the therapeutic potential of BPTS for treating patients with triple-negative breast cancer.

Keywords: Bolbostemma paniculatum (maxim.) Franquet, Total saponins, MDA-MB-231 cells, PI3K/Akt/mTOR, signaling pathway

\section{Background}

Because of the high incidence rate and complexity of the disease, breast cancer is the second largest cause of cancer-associated deaths in women worldwide. Triplenegative breast cancer (TNBC) with characteristics of early invasion, a propensity to metastasize and a relatively high rate of mortality amongst all breast cancer subtypes, accounts for $15-20 \%$ of all breast cancer cases [1]. In total,

\footnotetext{
* Correspondence: 410734436@qq.com

${ }^{6}$ Xi'an Hospital of Traditional Chinese Medicine Affiliated to Shaanxi University of Chinese Medicine, Xi'an, Shaanxi 710021, People's Republic of China

Full list of author information is available at the end of the article
}

four main subgroups of human breast tumors have been identified, luminal A (LA), luminal B (LB), human epidermal growth factor receptor 2 (Her2)-overexpressing and TNBC [2]. Patients with TNBC do not often benefit from currently available therapeutics due to the complexity and diversity of TNBC [3]. Treatment regimens currently used to treat patients with TNBC present with many issues, including poor prognosis, expense and severe pain $[4,5]$. Therefore, the development of novel therapeutics with fewer side effects and a relatively lower cost of production is required.

Traditional Chinese medicine may be viable alternative as patients may exhibit fewer side effects and are 
typically more economical [6-8]. Additionally, traditional Chinese medicines have been demonstrated to prevent and treat a number of diseases and may possess antiviral, anti-inflammatory, anticancer and immunosuppressive properties [9-11]. Bolbostemma paniculatum (Maxim.) Franquet (BP), referred to as Tu-bei-mu in China, is a member of Cucurbitaceae family [12]. BP has been used to treat breast cancer for $>200$ years following its inclusion in "Waike Zhengzhi Quansheng Ji" during the Qing dynasty [13]. Previous studies have demonstrated that BP has a number of constituents, including saponins, organic acids, sterols, and alkaloids, all of which possess beneficial pharmacological properties relevant to treating different types of cancer $[14,15]$. Total saponin is the primary active compound in $\mathrm{BP}$ and has been reported to inhibit the proliferation of MDA-MB-231 cells [16, 17]. However, the mechanisms of total saponin action are not yet understood.

The PI3K/Akt/mTOR signaling pathway serves an important role in proliferation and metastasis of tumor cells, and angiogenesis [18]. In addition, the PI3K/Akt/ mTOR signaling pathway has also been implicated in resistance to radiotherapy and chemotherapy [19]. Furthermore, the signaling pathway is frequently activated and serves a vital role in the progression of TNBC [20, 21]. Therefore, members of this pathway present as potential therapeutic targets for treating patients with TNBC. An increase in PI3K expression results in increased phosphorylation of Akt [22]. mTOR is a downstream target of p-Akt, which, when activated further regulates protein synthesis and promotes cell proliferation [23]. Therefore, the present study examined the effects of BP total saponin (BPTS) on TNBC and in particular the effects on the PI3K/Akt/mTOR signaling pathway.

The MDA-MB-231 cell line is the most common and representative cell line used to study TNBC [24]. It is a TNBC cell line and its use may contribute to a better understanding of molecular mechanisms of the initiation, proliferation and other aspects of TNBC. In the present study, MDA-MB-231 cells were used to examine the effects of BPTS on TNBC and the possible underlying mechanisms.

\section{Materials and methods Reagents}

BP was obtained from Beijing Tongrentang Group Co., Ltd. (Xi'an, China; specimen no. 20170306), and the sample identity was confirmed according to Chinese Pharmacopoeia. Dimethyl sulfoxide (DMSO), LY294002 and rapamycin were purchased from Sigma-Aldrich; Merck KGaA (Darmstadt, Germany). Cell Counting Kit8 (CCK-8) was obtained from 7Sea BioTech (Shanghai, China). Fetal bovine serum (FBS) and L-15 medium were purchased from Gibco; Thermo Fisher Scientific, Inc. (Waltham, MA, USA). All antibodies used for western blotting were purchased from CST Biological Reagents Co., Ltd. (Shanghai, China). Western blotting reagents were purchased from Hat BioTech Co., Ltd. (Xi'an, China). Apoptosis Detection kits were purchased from Nanjing KGI Biological Technology Development Co., Ltd. (Nanjing, China). Petroleum ether and nbutanol were purchased from Kemiou Chemical Reagent Co., Ltd. (Tianjin, China).

\section{Preparation of BPTS}

To prepare BPTS, 95\% ethanol was applied and refluxed with $1.0 \mathrm{~kg}$ dried BP for $2 \mathrm{~h}$ at $80^{\circ} \mathrm{C}$. Then, the ethanol was removed by rotary evaporator. The concentrated extract was resuspended in water. The water fraction was partitioned with petroleum ether followed by $\mathrm{n}$ butanol. The n-butanol fraction was allowed to evaporate, and the resultant sample was vacuum dried and crushed into a powder. Total saponin content was determined by UV spectroscopy at $472 \mathrm{~nm}$ (Persee, TU-1810, Beijing, China). Using this protocol, $36 \mathrm{~g}$ of a yellowish powder was obtained (yield, 3.6\%; total saponin content, $79.1 \%)$. The resultant powder was used for all subsequent experiments.

\section{Cell culture}

MDA-MB-231 cells were purchased from OBiO Technology Corp., Ltd. (Shanghai, China), and grown in L-15 supplemented with $10 \%$ FBS and $1 \%$ penicillinstreptomycin in a saturated humidity incubator $\left(37^{\circ} \mathrm{C}\right.$, $\left.5 \% \mathrm{CO}_{2}\right)$.

\section{CCK-8 assay}

Cell viability was determined using a CCK-8 assay according to the manufacturer's protocol. MDA-MB-231 cells were seeded at a density of $5 \times 10^{3}$ cells/well in a 96-well culture plate for $24 \mathrm{~h}$ after which the medium was changed and BPTS $(5,10,15 \mu \mathrm{g} / \mathrm{mL})$ was added and cultured for a further for 24,48 or $72 \mathrm{~h}$. $20 \mu \mathrm{l} \mathrm{CCK-8}$ reagent was added to each well and incubated for $4 \mathrm{~h}$. The optical density at $450 \mathrm{~nm}$ was measured using a Variskan ${ }^{\circ}$ Flash microplate reader (Thermo Scientific Fisher, Inc.).

\section{Apoptosis analysis by flow cytometry}

Annexin V-fluoroscein isothiocyanate (FITC)/propidium iodide (PI) double labeling was used to determine the apoptosis-inducing effect of BPTS on MDA-MB-231 cells. MDA-MB-231 cells were seeded into 6-well plates at a density of $1 \times 10^{6}$ cells per well, and incubated with BPTS for $48 \mathrm{~h}$ after which cells were trypsinized, collected and incubated with FITC-conjugated Annexin V and PI according to the manufacturer's instructions (BD 
Biosciences, San Jose, CA, USA). Apoptosis was measured by flow cytometry (BD FACSCalibur) and the data were analyzed using Cell Quest Research version 6.0 (BD Biosciences).

\section{Western blot analysis}

Proteins were extracted from MDA-MB-231 cells using RIPA buffer (Hart Biologicals, Ltd.) and the concentration was measured using a bicinchoninic acid assay. A total of $30 \mu \mathrm{g}$ protein was loaded into each lane of a $10 \%$ polyacrylamide gel and separated by SDS-PAGE. After the proteins were resolved, they were transferred to a PVDF membrane (EMD Millipore, Billerica, MA, USA). Membranes were blocked with 5\% non-fat dried milk, incubated with anti-PI3K (1:1000), anti-AKT (1:1000), anti-mTOR (1:1000), anti-p-PI3K (1:1000), anti-p-AKT (1:1000), anti-p-mTOR (1:1000) antibodies overnight at $4{ }^{\circ} \mathrm{C}$, and then incubated with the horseradish peroxidaseconjugated secondary antibodies (1:10000) for $2 \mathrm{~h}$ at room temperature. Enhanced chemiluminescence detection kits (EMD Millipore) were used to visualize bands, and intensity of the bands were quantified by 1.8 .0 version ImageJ (National Institutes of Health, Bethesda, MD, USA). Besides, actin was used to quantify the amount and integrity of the proteins. When inhibitors were employed, cells were pretreated for $3 \mathrm{~h}$ with inhibitor (LY294002, $20 \mu \mathrm{M}$; Rapamycin, $20 \mu \mathrm{M}$ ) before the addition of BPTS.

\section{Wound healing assay}

Wound healing assays were performed to determine the effects of BPTS on migration. A total of $5 \times 10^{4}$ cells were plated in each well of a 6-well plate. Once the confluence had reach $>90 \%$ a $200 \mu \mathrm{l}$ pipette tip was used to scratch five wounds in the cell layer. PBS was used to gently remove floating cells, and serum-free medium containing the aforementioned concentrations of BPTS was added to each well. The wounds were imaged at 0 , 12,24 and $48 \mathrm{~h}$ after scratching.

Migration rate $(\%)=($ Scratch distance at $0 \mathrm{~h}-$ scratch distance at indicated time)/Scratch distance at $0 \mathrm{~h} \times 100 \%$.

\section{Transwell migration assay}

A total of $3 \times 10^{4}$ cells were plated with or without BPTS into the upper chamber of a 24-well Transwell chamber separated by a polycarbonate filter. Serum-free medium was added to the upper chamber and medium containing 10\% FBS was added to the bottom chamber. After $48 \mathrm{~h}$, the cells on the top side of the inserts were scraped off, and the Transwell filters were stained with $0.1 \%$ crystal violet for $0.5 \mathrm{~h}$ at room temperature and counted using an inverted microscope (Nikon, Ti, Japan).

\section{Statistical analyses}

Data are expressed as the mean \pm standard error of mean. Statistical analyses were performed using one-way ANOVA in SPSS version 18.0 (IBM Corporation, Armonk, NY, USA) and Prism 5.0 (GraphPad Software, Inc., La Jolla, CA, USA). $P<0.05$ was considered to indicate a statistically significant.

\section{Results}

Inhibitory effect of BPTS on proliferation of MDA-MB-231 cells

Cell viability was assessed to determine the effect of BPTS on proliferation. BPTS significantly inhibited the proliferation of MDA-MB-231 cells in a dose- and timedependent manner (Fig. 1). The results show that cell viability was decreased following treatment with 10 and $15 \mu \mathrm{g} / \mathrm{mL}$ BPTS after 48 and $72 \mathrm{~h}$. Therefore, for all subsequent experiments, cells were treated with 5,10 and $15 \mu \mathrm{g} / \mathrm{mL}$ BPTS for $48 \mathrm{~h}$.

\section{Apoptosis-inducing effect of BPTS on MDA-MB-231 cells}

The proportion of apoptotic cells increased significantly concurrent with an increase in BPTS concentration (Fig. 2). The proportion of apoptotic cell with 5, 10 and $15 \mu \mathrm{g} / \mathrm{mL}$ BPTS was $7.54,11.48$ and $16.29 \%$, respectively. These results suggest that BPTS induced apoptosis in MDA-MB-231 cells.

\section{Pathway-related mechanisms of the apoptotic effects of BPTS}

To investigate the role of $\mathrm{PI} 3 \mathrm{~K} / \mathrm{Akt} / \mathrm{mTOR}$ pathway in BPTS-induced apoptosis, the protein expression levels of PI3K, Akt, mTOR, p-PI3K, p-Akt and pmTOR were examined by western blot. The levels of p-PI3K, p-Akt and p-mTOR in MDA-MB-231 cells

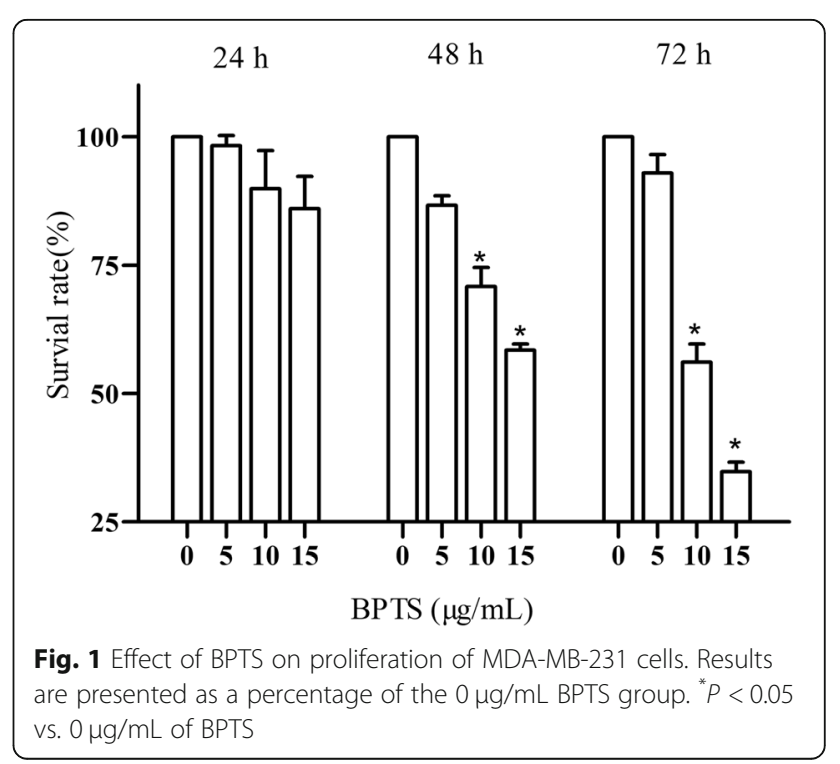




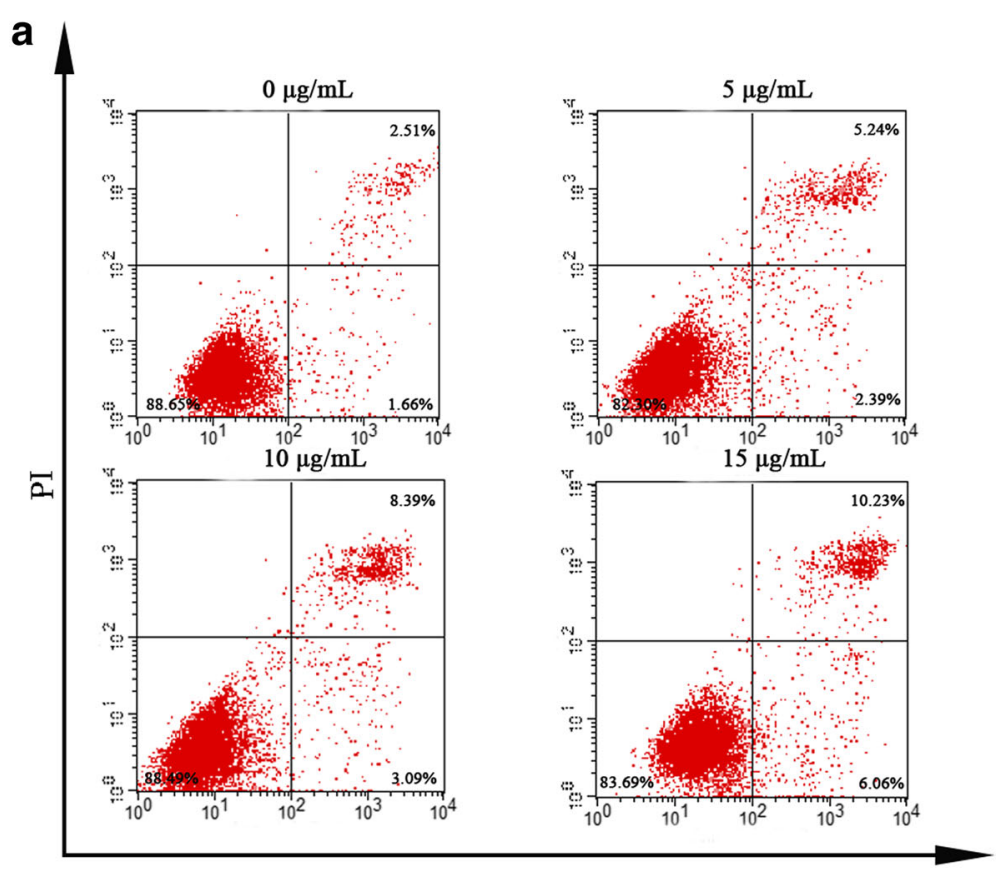

Annexin V-FITC

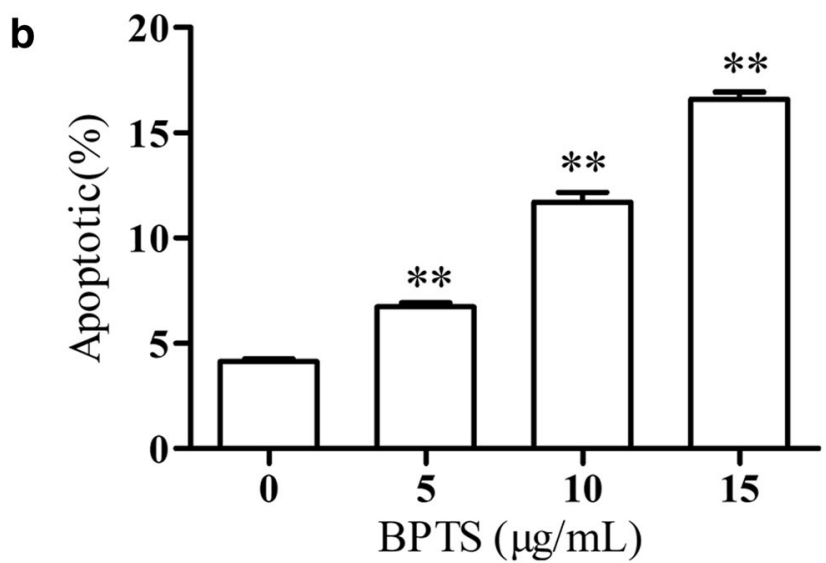

Fig. 2 Flow cytometry analysis of apoptosis in MDA-MB-231 cells. a Representative images of flow cytometry. b Apoptotic rates in cells treated with the stated concentrations of BPTS. ${ }^{* *} P<0.01$ vs. $0 \mu \mathrm{g} / \mathrm{mL}$ of BPTS

treated with BPTS were decreased (Fig. 3). To confirm that BPTS induced apoptosis via the PI3K/Akt/mTOR pathway, cells were treated with a PI3K inhibitor (LY294002) prior to treatment with BPTS. Treatment with LY294002 reduced the levels of Akt phosphorylation. As Akt has many downstream targets, to determine whether mTOR was involved in BPTS-induced apoptosis, rapamycin, which is an mTOR inhibitor, was added to verify the mechanisms. The levels of p-mTOR was decreased when rapamycin intervening, the same as BPTS. These data suggest that BPTS initiates apoptosis by inhibiting the PI3K/Akt/mTOR signaling pathway.
BPTS decreases the migratory capacity of MDA-MB-231 cells Following treatment with the inhibitors for 12,24 and $48 \mathrm{~h}$, the migratory capacity of cells was observed and imaged. The migration distance of cells treated with the inhibitors was decreased compared with the control cells (Fig. 4). There was an inverse relationship between the concentration of the treatment used and the distance migrated. In the Transwell assay, the effect of BPTS on migration was examined. BPTS significantly decreased the number of invaded cells.

\section{Discussion}

In modern medicine, surgery, chemotherapy and radiation are frequently used for treating patients with 


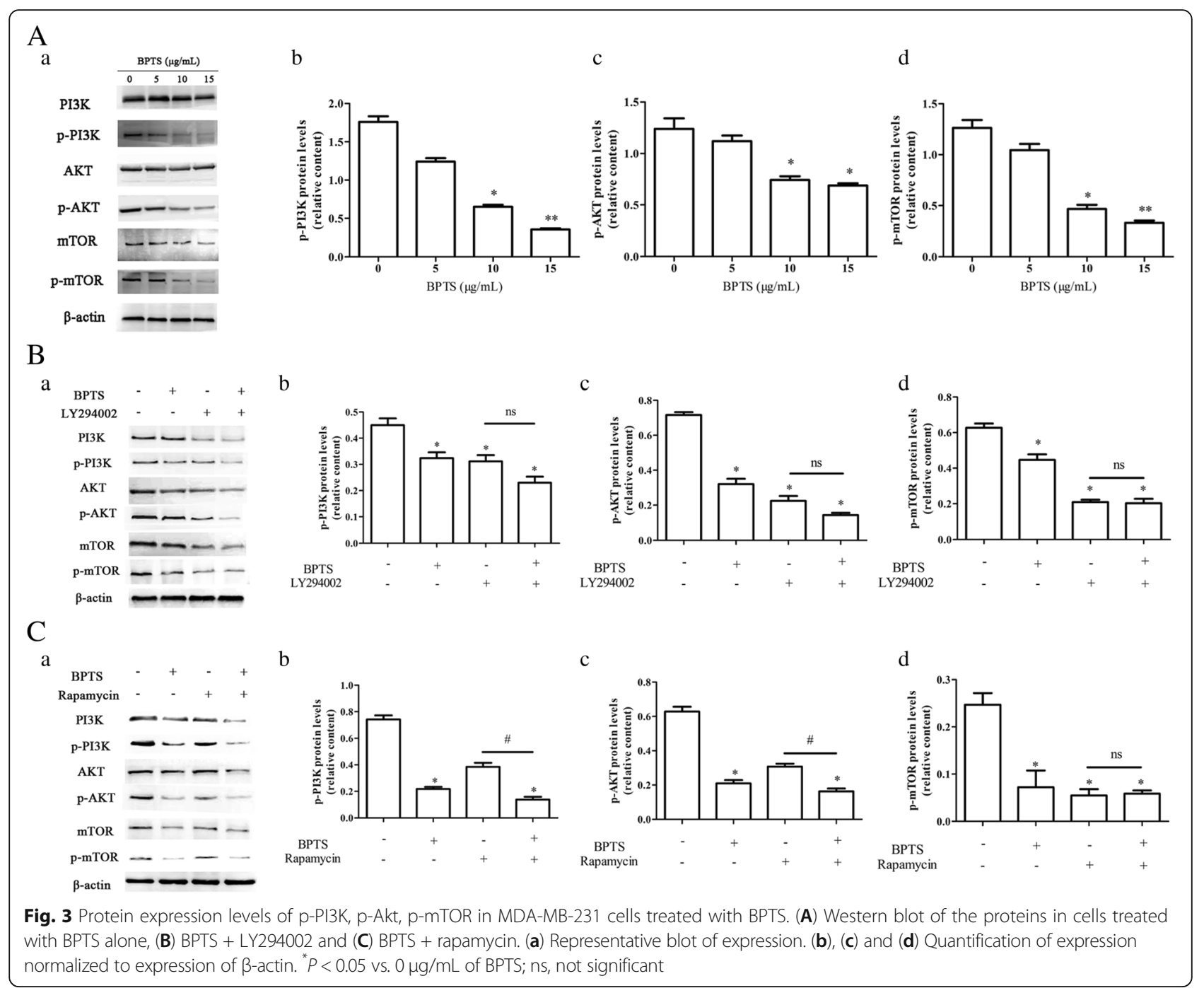

TNBC $[25,26]$. However, these options are expensive, and patients exhibit high rates of recurrence and will frequently have a poor prognosis [27]. Therefore, an effective and economical treatment regimen for treating patients with TNBC is desirable. The study of using herbs and traditional Chinese medicines as alternatives or adjuvants to conventional treatments has gained traction, as a result of the possiblity of reduced side effects and improved therapeutic outcomes [28, 29]. BP is a traditional medicine that has been widely used in certain regions to prevent and treat many diseases, including, glioblastoma, prostate cancer, non-small cell lung cancer and colorectal cancer [30]. Treatment with Tu-bei-mu saponin preparations did result in some side effects in clinical studies at higher doses, including toxicity, allergic reactions and hemolysis. Previous works made a contribution to our work. Tubeimoside I, the respective major active ingredient of BPTS, may show antitumor activities [14]. Additonally, BPTS may initiate an allergic reaction when injected with Tu-bei-mu saponin [31].

In the present study, the effects and mechanisms of BPTS on MDA-MB-231 cells were examined. MDAMB-231 cells are a well-studied TNBC cell line [32, 33]. MDA-MB-231 cells do not express ER, PR and Her2, and the majority of the frequently used therapeutics target one of these receptors. Therefore, this cell line is commonly used to research TNBC [34]. In the present study, the CCK-8 cell viability assay demonstrated that BPTS decreased the proliferation of MDA-MB-231 cells in a time-dependent and dose-dependent manner, with $\mathrm{IC}_{50}$ values varying from 5 to $15 \mu \mathrm{g} / \mathrm{mL}$ and also induced apoptosis. Furthermore, the migratory ability of MDAMB-231 cells was decreased by BPTS treatment. The protein expression levels of $\mathrm{p}$-PI3K, $\mathrm{p}$-Akt and $\mathrm{p}$-mTOR were all decreased following treatment with BPTS, and activation of the PI3K/Akt/mTOR signaling pathway has 


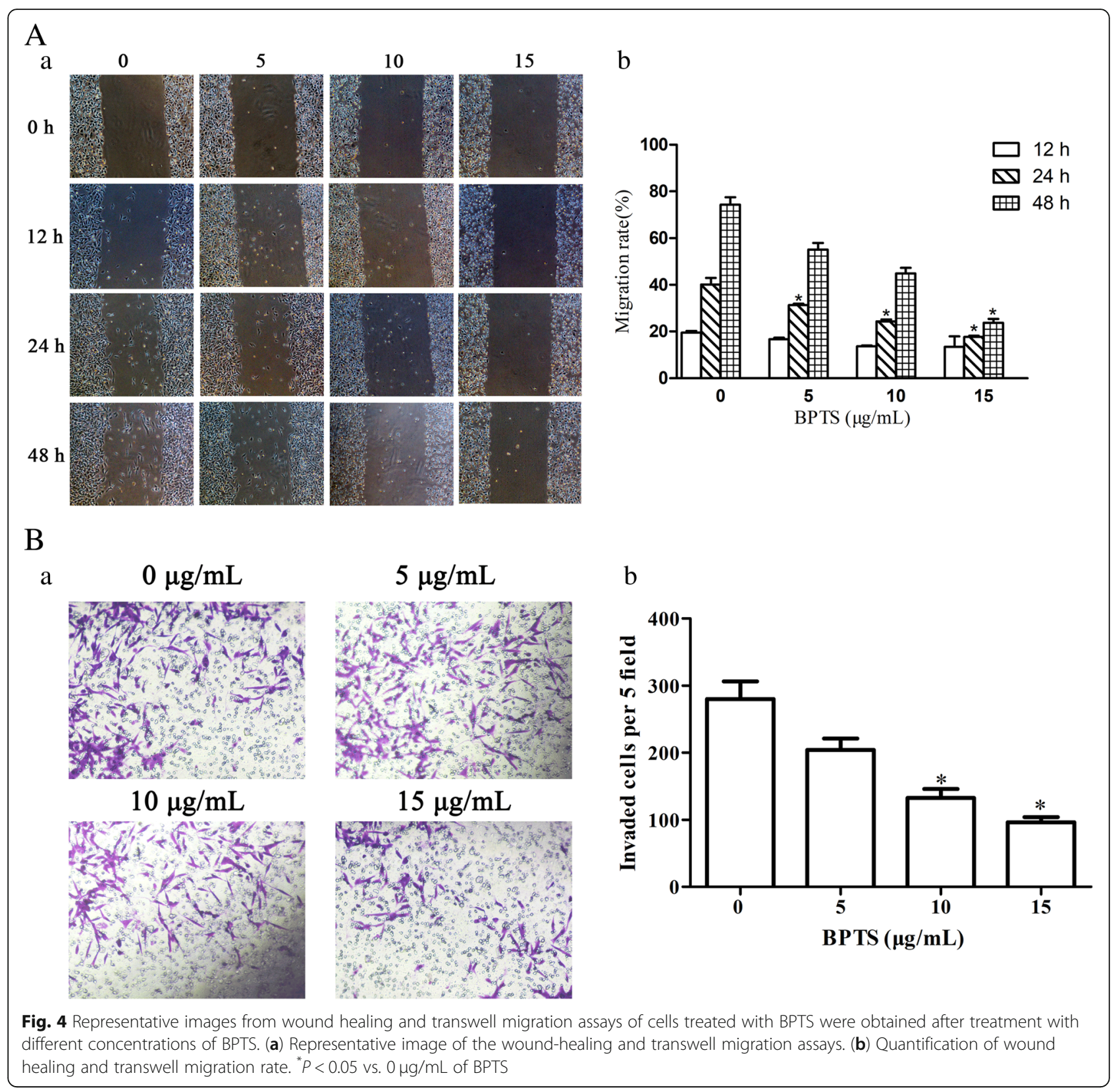

been demonstrated to promote proliferation, differentiation and survival of MDA-MB-231 cells [35].

The apoptotic pathways are the most important pathways resulting in cell death [36, 37]. However, resistence to apoptosis allows MDA-MB-231 cells to proiliefrate. In the present study, inhibiting the PI3K/Akt/mTOR signaling pathway induced apoptosis in agreement with previous studies [38, 39]. The expression of apoptosis markers, such as p53, caspases, Bax and Bcl-2 have all been demonstrated in MDA-MB-231 cells [40]. p53 is a downstream target of the PI3K/Akt/mTOR signaling pathway, and p53 upregulates Bax, which then activates caspases, resulting in apoptosis [41]. Inhibition of PI3K/
Akt/mTOR pathway can affect multiple apoptosis inducing proteins [42]. Therefore it was hypothesized that the PI3K/Akt/mTOR signaling pathway was involved in BPTS-induced apoptosis.

To determine whether the PI3K/Akt/mTOR signaling pathway was able to affect migration in MDA-MB231 cells, wound healing and Transwell migration assays were performed at a range of concentrations and treatment durations. Consistent with previous reports, inhibition of the PI3K/Akt/mTOR signaling pathway reduced the migration of cells. Migrating cells have been demonstrated to express increased levels of PI3K [43]. PI3K functions to recruit proteins containing Akt 
to the membrane, which can then be activated by PI3K-dependent kinase 1 and PI3K-dependent kinase 2 [44]. Activation of Akt in turn activates mTOR. Therefore, the PI3K/Akt/mTOR signaling pathway may function to regulate cell motility [45]. In MDAMB-231 cells, the Akt family members mediate migration, proliferation, survival and protein synthesis [46]. In the present study, BPTS decreased Akt activation by decreasing the protein expression levels of PI3K, and this may have have modulated the migratory capacity of MDA-MB-231 cells.

Previous studies have demonstrated that several key molecules and signaling pathways regulate apoptosis in MDA-MB-231 cells [47, 48]. Among the signaling pathways, the PI3K/Akt/mTOR signaling pathway has been well-studied and has been demonstrated to regulate cell survival, proliferation and differentiation [41]. Inhibitors of the PI3K/Akt/mTOR signaling pathway may therefore prevent survival and induce apoptosis in TNBC cells. PI3K, was discovered $>20$ years ago, and its role in metabolism, growth, survival and motility has been extensively studied [49]. Akt promotes cell survival and also abrogates the negative regulatory effect of the transcription factor NF- $\kappa B$, resulting in an increase in transcription of anti-apoptotic and pro-survival genes [50]. mTOR is a highly conserved serine/threonine kinase, and its expression regulates metabolism and growth, and additionally integrates the signals from many stimuli [51]. Phosphorylation of these proteins is an important regulatory mechanism that results in conformational changes of many enzymes and receptors, resulting in their activation/ deactivation [52]. In the present study, treatment of MDA-MB-231 cells with BPTS decreased the levels of phosphorylated PI3K, Akt and mTOR. These results suggest that BPTS may induce apoptosis of MDA-MB-231 cells through the PI3K/Akt/mTOR pathway.

BPTS could reduce migration and induce apoptosis of MDA-MB-231 cells through the PI3K/Akt/mTOR signaling pathway. Together, these data provide insight into the anti-tumor activity of BPTS and the underlying mechanisms. BPTS may be a potentially novel and effective treatment option for patients with TNBC.

\section{Conclusions}

In conclusion, BPTS decreases proliferation, migration and apoptosis of MDA-MB-231 cells through the PI3K/ Akt/mTOR pathway. These results provide a new theoretical basis for use of BPTS in a clinical setting, although additional in vivo studies are required. However, as only the MDA-MB-231 cell line was used, other TNBC cell lines need to be studied. Additional research into the mechanisms and potential clinical uses of BPTS are required.

\section{Abbreviations}

BP: Bolbostemma paniculatum (Maxim.) Franquet; BPTS: BP total saponins; DMSO: Dimethyl sulfoxide; Her2: Human epidermal growth factor receptor 2; LA: Luminal A; LB: Luminal B; TNBC: Triple-negative breast cancer

\section{Acknowledgements}

The authors would like to thank all the members of The Laboratory Animal Center of Xi'an Jiaotong University.

Ethic approval and consent to participate

Not applicable.

\section{Authors'contributions}

DJW and LXQ designed the study. SRG, LKL, GZZ, YK, YXJ, LYW and YJ completed the experiment. ZYY and $\mathrm{HQ}$ analyzed data and wrote the manuscript. All authors have approved the final version.

\section{Funding}

The present study was was supported by grants from The National Natural Science Foundation of China (grant nos. 81573983, 81873311 and 81674028) and Health Commission of Xi'an city Subject (grant no. SZJ201907).

\section{Availability of data and materials}

The datasets used and analyzed during the current study available from the corresponding author on reasonable request.

\section{Consent for publication}

Not applicable.

\section{Competing interests}

The authors declare that they have no competing interests.

\section{Author details \\ ${ }^{1}$ School of Pharmacy, Xi'an Jiaotong University, Xi'an, Shaanxi 710061, People's Republic of China. ${ }^{2}$ Shaanxi Key Laboratory of "Qiyao" Resources And Anti-tumor Activities, Xi'an, Shaanxi 710061, People's Republic of China. ${ }^{3}$ Department of Ophthalmology, Affiliated Guangren Hospital of Xi'an Jiaotong University, Xi'an, Shaanxi 710004, People's Republic of China. ${ }^{4}$ Department of Ophthalmology, Xi'an No.4 Hospital, Xi'an, Shaanxi 710004, People's Republic of China. ${ }^{5}$ School of Basic Medicine, Gansu University of Chinese Medicine, Lanzhou, Gansu 730000, People's Republic of China. ${ }^{6}$ Xi'an Hospital of Traditional Chinese Medicine Affiliated to Shaanxi University of Chinese Medicine, Xi'an, Shaanxi 710021, People's Republic of China.}

Received: 30 May 2019 Accepted: 2 October 2019

Published online: 08 November 2019

\section{References}

1. Bosch A, Eroles P, Zaragoza R, Vina JR, Lluch A. Triple-negative breast cancer: molecular features, pathogenesis, treatment and current lines of research. Cancer Treat Rev. 2010;36(3):206-15.

2. Wu CY, Qiu SL, Liu P, Ge YQ, Gao XF. Rhizoma Amorphophalli inhibits TNBC cell proliferation, migration, invasion and metastasis through the PI3K/Akt/ mTOR pathway. J Ethnopharmacol. 2018;211:89-100.

3. Wei WS, Zou YF, Jiang QH, Zhou ZB, Ding HL, Yan LP, Yang SX. PSMB5 is associated with proliferation and drug resistance in triple-negative breast cancer. Int J Biol Marker. 2018;33(1):102-8.

4. Bui-Xuan NH, Tang PMK, Wong CK, Fung KP. Photo-activated pheophorbide-a, an active component of Scutellaria barbata, enhances apoptosis via the suppression of ERK-mediated autophagy in the estrogen receptor-negative human breast adenocarcinoma cells MDA-MB-231. J Ethnopharmacol. 2010;131(1):95-103.

5. Foo JB, Yazan LS, Tor YS, Wibowo A, Ismail N, Armania N, Cheah YK, Abdullah R. Dillenia suffruticosa dichloromethane root extract induced apoptosis towards MDA-MB-231 triple-negative breast cancer cells. J Ethnopharmacol. 2016:187:195-204.

6. Wang W, Xu L, Shen CY. Effects of traditional Chinese medicine in treatment of breast Cancer patients after mastectomy: a meta-analysis. Cell Biochem Biophys. 2015;71(3):1299-306.

7. Xue JX, Zhu ZY, Bian WH, Yao C. The traditional Chinese medicine Kangai injection as an adjuvant method in combination with chemotherapy for the 
treatment of breast Cancer in Chinese patients: a meta-analysis. Evid-Based Compl Alt. 2018;12:1-16

8. Cohen I, Tagliaferri M, Tripathy D. Traditional Chinese medicine in the treatment of breast cancer. Semin Oncol. 2002;29(6):563-74.

9. Parvez MK, Alam P, Arbab AH, Al-Dosari MS, Alhowiriny TA, Alqasoumi SI. Analysis of antioxidative and antiviral biomarkers beta-amyrin, betasitosterol, lupeol, ursolic acid in Guiera senegalensis leaves extract by validated HPTLC methods. Saudi Pharm J. 2018;26(5):685-93.

10. Yiemwattana I, Chaisomboon N, Jamdee K. Antibacterial and antiinflammatory potential of Morus alba stem extract. Open Dent J. 2018; 12:388.

11. Palmer DG. Anti-inflammatory effects of mussel extracts. New Zeal Med J. 1980;92(670):328

12. Hu MX, Zhao M, An C, Yang M, Li QW, Zhang Y, Suetsugu A, Tome $Y$, Yano $\mathrm{S}$, Fu YL, et al. Real-time imaging of apoptosis induction of human breast Cancer cells by the traditional Chinese medicinal herb Tubeimu. Anticancer Res. 2012;32(7):2509-14.

13. Jianwei $D$, Yun $H$, Yiqi $Y$, Jie $Z$, Fengming $Y$. The exposition of the theory on Yanghe decoction treating breast Cancer. World Chinese Med. 2015;10(2):196-8.

14. Zeng Y, Lu Y, Chen Z, Tan J, Bai J, Li P, Wang Z, Du S. Rapid characterization of components in Bolbostemma paniculatum by UPLC/LTQ-Orbitrap MS(n) analysis and multivariate statistical analysis for herb discrimination. Molecules. 2018;23(5):1155.

15. Tang Y, Li W, Cao J, Li W, Zhao Y. Bioassay-guided isolation and identification of cytotoxic compounds from Bolbostemma paniculatum. J Ethnopharmacol. 2015;169:18-23.

16. Chao A, Mingxin $H$, Yanling $F$, Kaiwen $H$, Minghuan Z. Effect of saponins of Bolbostemma paniculatum on human breast cancer cells MDA-MB-231 (GFP) and MCF-7 (GFP) transfected with green fluorescent protein gene. J Tradit Chin Med. 2014;55(13):1136-8.

17. Chao A, Meng $Y$, Mingxin $H$, Yanling $F$, Quanwang $L$, Yang $C M$, Hoffman $R$, Hui $Q$, Yonggang $L$, Kaiwen $H$. Study on anticancer effects of extract of Tubeimu on mouse model of human breast cancer MDA- MB -231-GFP. Chin Arch Tradit Chin Med. 2013;28(2):390-3.

18. Li N, Wang WQ, Xu B, Gong HY. miR-196b regulates gastric cancer cell proliferation and invasion via PI3K/AKT/mTOR signaling pathway. Oncol Lett. 2016:11(3):1745-9.

19. Burris HA. Overcoming acquired resistance to anticancer therapy: focus on the PI3KJAKT/mTOR pathway. Cancer Chemoth Pharm. 2013;71(4):829-42.

20. Deng M, Wang JG, Chen YB, Zhang LK, Liu DC. Combination of SF1126 and gefitinib induces apoptosis of triple-negative breast cancer cells through the PI3KJAKT-mTOR pathway. Anti-Cancer Drug. 2015;26(4):422-7.

21. Massihnia D, Galvano A, Fanale D, Perez A, Castiglia M, Incorvaia L, Listi A, Rizzo S, Cicero G, Bazan V, et al. Triple negative breast cancer: shedding light onto the role of pi3k/akt/mtor pathway. Oncotarget. 2016;7(37):60712-22

22. Li XQ, Lu Y, Liang K, Liu BL, Fan Z. Differential responses to doxorubicininduced phosphorylation and activation of Akt in human breast cancer cells. Breast Cancer Res. 2005;7(5):R589-97.

23. Lu Q, Zhou Y, Hao M, Li C, Wang J, Shu F, Du L, Zhu X, Zhang Q, Yin X. The mTOR promotes oxidative stress-induced apoptosis of mesangial cells in diabetic nephropathy. Mol Cell Endocrinol. 2018;473:31-43.

24. Ko YS, Lee WS, Joo YN, Choi YH, Kim GS, Jung JM, Ryu CH, Shin SC, Kim HJ. Polyphenol mixtures of Euphorbia supina the inhibit invasion and metastasis of highly metastatic breast cancer MDA-MB-231 cells. Oncol Rep. 2015;34(6):3035-42.

25. Jiang M, Xiao Y, Liu D, Luo N, Gao Q, Guan Y. Overexpression of long noncoding RNA LINC01296 indicates an unfavorable prognosis and promotes tumorigenesis in breast cancer. Gene. 2018;675:217-24.

26. Steenbruggen TG, Linn SC, Rodenhuis S, Sonke GS. Ongoing remission nineteen years after high-dose chemotherapy for Oligometastatic breast Cancer; what can we learn from this patient? Cureus. 2015;7(12):e433.

27. Zhao S, Ma WJ, Zhang MH, Tang DB, Shi QT, Xu SQ, Zhang XS, Liu YP, Song $Y$, Liu LY, et al. High expression of CD147 and MMP-9 is correlated with poor prognosis of triple-negative breast cancer (TNBC) patients. Med Oncol. 2013;30(1):335

28. He K, Li XG, Chen X, Ye XL, Huang J, Jin YN, Li PP, Deng YF, Jin Q, Shi $Q$, et al. Evaluation of antidiabetic potential of selected traditional Chinese medicines in STZ-induced diabetic mice. J Ethnopharmacol. 2011;137(3):1135-42.
29. Lin HY, Zhao Y, Yu JN, Jiang WW, Sun XL. Effects of traditional Chinese medicine Wei-Wei-Kang-granule on the expression of Egfr and Nf-kb in chronic atrophic gastritis rats. Afr J Tradit Complem. 2012;9(1):1-7.

30. Cheng G, Zhang Y, Zhang X, Tang HF, Cao WD, Gao DK, Wang XL. Tubeimoside $V(1)$, a new cyclic bisdesmoside from tubers of Bolbostemma paniculatum, functions by inducing apoptosis in human glioblastoma U87MG cells. Bioorg Med Chem Lett. 2006;16(17):4575-80.

31. Zhang T, Han S, Liu Q, Guo Y, He L. Analysis of allergens in tubeimu saponin extracts by using rat basophilic leukemia $2 \mathrm{H} 3$ cell-based affinity chromatography coupled to liquid chromatography and mass spectrometry. J Sep Sci. 2014;37(22):3384-91.

32. Li ZL, Lim SK, Liang X, Lim YP. The transcriptional coactivator WBP2 primes triple-negative breast cancer cells for responses to Wnt signaling via the JNK/Jun kinase pathway. J Biol Chem. 2018;293(52):20014-28.

33. Griffith J, Andrade D, Mehta M, Berry W, Benbrook DM, Aravindan N, Herman TS, Ramesh R, Munshi A. Silencing BMI1 radiosensitizes human breast cancer cells by inducing DNA damage and autophagy. Oncol Rep. 2017;37(4):2382-90.

34. Lewinska A, Adamczyk-Grochala J, Kwasniewicz E, Deregowska A, Wnuk M. Diosmin-induced senescence, apoptosis and autophagy in breast cancer cells of different p53 status and ERK activity. Toxicol Lett. 2017:265:117-30.

35. Park JH, Kim KP, Ko JJ, Park KS. PI3KNAkt/mTOR activation by suppression of ELK3 mediates chemosensitivity of MDA-MB-231 cells to doxorubicin by inhibiting autophagy. Biochem Bioph Res Co. 2016;477(2):277-82.

36. Duan HL, Li Y, Lim HY, Wang WD. Identification of 5-nitrofuran-2-amide derivatives that induce apoptosis in triple negative breast cancer cells by activating C/EBP-homologous protein expression. Bioorgan Med Chem. 2015;23(15):4514-21.

37. Shrivastava S, Jeengar MK, Reddy VS, Reddy GB, Naidu VGM. Anticancer effect of celastrol on human triple negative breast cancer: possible involvement of oxidative stress, mitochondrial dysfunction, apoptosis and PI3K/Akt pathways. Exp Mol Pathol. 2015;98(3):313-27.

38. Dirican A, Atmaca H, Bozkurt E, Erten C, Karaca B, Uslu R. Novel combination of docetaxel and thymoquinone induces synergistic cytotoxicity and apoptosis in DU-145 human prostate cancer cells by modulating PI3K-AKT pathway. Clin Transl Oncol. 2015;17(2):145-51.

39. Sun YH, Xu YH, Xu J, Lu D, Wang JY. Role of TM4SF1 in regulating breast cancer cell migration and apoptosis through PI3K/AKT/mTOR pathway. Int J Clin Exp Pathol. 2015:8(8):9081-8.

40. Zhang MC, Guo RB, Zhai YF, Yang DJ. LIGHT sensitizes IFN gammamediated apoptosis of MDA-MB-231 breast cancer cells leading to downregulation of anti-apoptosis Bcl-2 family members. Cancer Lett. 2003;195(2): 201-10.

41. Kamal A, Nayak VL, Nagesh N, Vishnuvardhan MVPS, Reddy NVS. Benzo [b] furan derivatives induces apoptosis by targeting the PI3K/Akt/mTOR signaling pathway in human breast cancer cells. Bioorg Chem. 2016;66:12431.

42. Pathania AS, Guru SK, Verma MK, Sharma C, Abdullah ST, Malik F, Chandra S, Katoch M, Bhushan S. Disruption of the PI3K/AKT/mTOR signaling cascade and induction of apoptosis in HL-60 cells by an essential oil from Monarda citriodora. Food Chem Toxicol. 2013;62:246-54.

43. Du J, Sun CQ, Hu ZZ, Yang Y, Zhu YC, Zheng DT, Gu L, Lu XA. Lysophosphatidic Acid Induces MDA-MB-231 Breast Cancer Cells Migration through Activation of PI3K/PAK1/ERK Signaling. PLOS One. 2010;5(12):1-10.

44. Wander SA, Zhao DK, Besser AH, Hong F, Wei JQ, Ince TA, Milikowski C, Bishopric NH, Minn AJ, Creighton CJ, et al. PI3K/mTOR inhibition can impair tumor invasion and metastasis in vivo despite a lack of antiproliferative action in vitro: implications for targeted therapy. Breast Cancer Res Tr. 2013; 138(2):369-81.

45. Penuel E, Martin GS. Transformation by v-Src: Ras-MAPK and PI3K-mTOR mediate parallel pathways. Mol Biol Cell. 1999;10(6):1693-703.

46. Tao JJ, Castel P, Radosevic-Robin N, Elkabets M, Auricchio N, Aceto N, Weitsman G, Barber P, Vojnovic B, Ellis $\mathrm{H}$, et al. Antagonism of EGFR and HER3 enhances the response to inhibitors of the PI3K-Akt pathway in triplenegative breast Cancer. Sci Signal. 2014;7(318):1-19.

47. Li P, Tian WX, Ma XF. Alpha-mangostin inhibits intracellular fatty acid synthase and induces apoptosis in breast cancer cells. Mol Cancer. 2014:13:138.

48. Gao YG, Ge ZC, Zhang ZT, Bai ZG, Ma XM, Wang Y. Vascular endothelial growth inhibitor affects the invasion, apoptosis and vascularisation in breast cancer cell line MDA-MB-231. Chinese Med J-Peking. 2014;127(10):1947-53. 
49. Dey N, De P, Leyland-Jones B. PI3K-AKT-mTOR inhibitors in breast cancers: from tumor cell signaling to clinical trials. Pharmacol Therapeut. 2017;175:91-106.

50. Woo SU, Sangai T, Akcakanat A, Chen H, Wei C, Meric-Bernstam F. Vertical inhibition of the PI3K/Akt/mTOR pathway is synergistic in breast cancer. Oncogenesis. 2017;6:e385.

51. Xie ZZ, Li MM, Deng PF, Wang S, Wang L, Lu XP, Hu LB, Chen Z, Jie HY, Wang YF, et al. Paris saponin-induced autophagy promotes breast cancer cell apoptosis via the Akt/mTOR signaling pathway. Chem Biol Interact. 2017;264:1-9.

52. Nishina A, Miura A, Goto M, Terakado K, Sato D, Kimura H, Hirai Y, Sato H, Phay N. Mansonone E from Mansonia gagei inhibited alpha-MSH-induced Melanogenesis in B16 cells by inhibiting CREB expression and phosphorylation in the PI3K/Akt pathway. Biol Pharm Bull. 2018;41(5):770-6.

\section{Publisher's Note}

Springer Nature remains neutral with regard to jurisdictional claims in published maps and institutional affiliations.

Ready to submit your research? Choose BMC and benefit from:

- fast, convenient online submission

- thorough peer review by experienced researchers in your field

- rapid publication on acceptance

- support for research data, including large and complex data types

- gold Open Access which fosters wider collaboration and increased citations

- maximum visibility for your research: over $100 \mathrm{M}$ website views per year

At BMC, research is always in progress.

Learn more biomedcentral.com/submissions 